\title{
Riscos na rotina de trabalho de agentes comunitários de saúde de uma Equipe de Saúde da Família
}

Risk in the workplace of Community Health Workers of a family health team

Riesgos en la rotina de trabajo de Agentes Comunitários de Salud de un equipo de salud de la familia

\author{
Karine da Silva MOREIRA ${ }^{(1)}$ \\ Maria Luiza Rêgo BEZERRA ${ }^{(2)}$ \\ Cecilma Miranda de Sousa TEIXEIRA ${ }^{(3)}$ \\ Simony Fabíola Lopes NUNES ${ }^{(4)}$
}

Recebido: 12 jul 2019 Revisado: 22 jul 2019 Aceito: 27 jul 2019

Autor de correspondência: Maria Luiza Rêgo Bezerra marialuizaregobezerra@gmail.com

Conflito de interesses: Os autores declaram não haver nenhum interesse profissional ou pessoal que possa gerar conflito de interesses em relação a este manuscrito.

\section{Resumo}

Os Agentes Comunitário de Saúde estão sujeitos a situações de risco frente às suas responsabilidades no âmbito da Atenção Primária em Saúde, destarte, este estudo de caráter descritivo de abordagem quali-quantitativa com o objetivo de investigar os riscos na rotina de trabalho destes profissionais da Equipe de Saúde da Família do Parque Anhanguera em Imperatriz, MA. Coletaram-se os dados em entrevista com questionário semiestruturado, após assinatura do termo de consentimento e aprovação no Comitê de Ética do Hospital Universitário da Universidade Federal do Maranhão sob o parecer 177.582. Os resultados obtidos foram apresentados em tabelas e gráfico através do programa Excel $\circledast$ e as questões qualitativas descritas de acordo com os objetivos, tendo sido os sujeitos identificados por nomes de pedras preciosas. Os resultados demonstraram que $100 \%$ foram do sexo feminino; $60 \%$ com idade de 31 a 55 anos e casadas; $100 \%$ com renda mensal de 1 a 2 salários mínimos; $80 \%$ atendiam até 149 famílias; $100 \%$ realizavam de 20 a 40 visitas semanais com carga horária de $8 \mathrm{~h} / \mathrm{dia}$. Concluiu-se que, dentre os riscos, predominaram os biológicos e físicos, durante as visitas domiciliares. Já no perfil, o predomínio foi o sexo feminino, casada, ensino médio, renda familiar de 1 a 2 salários mínimos. Sugerem-se novas pesquisas com maior universo para consolidar estes achados e fomentar medidas públicas preventivas dos riscos.

Descritores: Assunção de Riscos; Agentes Comunitários de Saúde; Estratégia Saúde da Família. 


\begin{abstract}
The Community Health Agent is subject to risk situations in the context of Primary Health Care, in this descriptive study of a qualitative and quantitative approach with the objective of investigating the risks in the routine work of these professionals of the Team of Family Health in the Anhanguera Park in Imperatriz-MA. The data were collected in an interview with a semi-structured questionnaire, after signing the consent form and approval in the Ethics Committee of the University Hospital of the Federal University of Maranhão under the opinion 177,582. The results obtained were presented in tables and graph through Excel ${ }^{\circledR}$ program and the qualitative questions described according to the objectives, being the subjects identified by names of precious stones. The results showed that $100 \%$ were female; $60 \%$ aged 31 to 55 years and married; $100 \%$ with monthly income of 1 to 2 minimum wages; $80 \%$ served up to 149 families; $100 \%$ performed from 20 to 40 visits per week with a work load of $8 \mathrm{~h} /$ day. It was concluded that, among the risks, biological and physical factors predominated during home visits. In the profile, the predominance was female, married, high school, family income of 1 to 2 minimum wages. Further research with a larger universe is suggested to consolidate these findings and to foment public preventive measures of the risks.
\end{abstract}

Keywords: Risk-Taking; Community Health Workers; Family Health Strategy.

\begin{abstract}
Resumen
Los agentes comunitarios de salud están sujetos a situaciones de riesgo frente a sus responsabilidades en el ámbito de la Atención Primaria en Salud, destete, este estudio de carácter descriptivo de abordaje cualitativo cuantitativo con el objetivo de investigar los riesgos en la rutina de trabajo de estos profesionales del Equipo de Salud de la Familia del Parque Anhanguera en Emperatriz-MA. Se recogen los datos en una entrevista con un cuestionario semiestructurado, tras la firma del término de consentimiento y aprobación en el Comité de Ética del Hospital Universitario de la Universidad Federal de Maranhão bajo el parecer 177.582. Los resultados obtenidos fueron presentados en tablas y gráficos a través del programa Excel ${ }^{\circledR}$ y las cuestiones cualitativas descritas de acuerdo con los objetivos, siendo los sujetos identificados por nombres de piedras preciosas. Los resultados demostraron que el $100 \%$ fue del sexo femenino; $60 \%$ con edad de 31 a 55 años y casadas; $100 \%$ con renta mensual de 1 a 2 salarios mínimos; El $80 \%$ atendía a 149 familias; $100 \%$ realizaban de 20 a 40 visitas semanales con carga horaria de 8h/día Se concluyó que, entre los riesgos, predominaron los biológicos y físicos, durante las visitas domiciliarias. En el perfil, el predominio fue el sexo femenino, casada, secundaria, ingreso familiar de 1 a 2 salarios mínimos. Se sugieren nuevas investigaciones con mayor universo para consolidar estos hallazgos y fomentar medidas públicas preventivas de los riesgos.
\end{abstract}

Palabras-claves: Asúncion de Riesgos; Agentes Comunitários de Salud; Estrategia de Salud Familiar.

\title{
Introdução
}

A saúde dos trabalhadores diz respeito a um campo do saber que visa compreender as relações entre o trabalho e o processo saúde/doença. ${ }^{1}$

Neste aspecto, há de se considerar os riscos relacionados ao trabalho, que, trata-se de qualquer chance de que ocorra um dano à saúde do trabalhador por meio de um 
componente ou situação existente no ato de trabalhar e no ambiente. Tal fato pode ocorrer a partir de acidentes, patologias ou pela poluição existente no ambiente de trabalho. No entanto, o dano pode ocorrer não tão somente ao trabalhador isolado, mas até mesmo aos integrantes de sua própria família. ${ }^{2}$

Assim, o Ministério da Saúde classifica em cinco grupos, os riscos ocupacionais, que correspondem a riscos físicos que incluem dentre outros ruídos, vibração, temperaturas extremas de frio e calor e pressão atmosférica anormal; químicos como exposição a agentes e substâncias químicas, poeiras minerais e vegetais; biológicos que envolvem micro-organismos patológicos como vírus, bactérias, parasitas e outros; ergonômicos e psicossociais que tratam respectivamente da organização do trabalho e gestão do mesmo; mecânicos e de acidentes são relacionados a qualquer situação que pode levar a ocorrência de acidentes no trabalho, como por exemplo, a não utilização de Equipamentos de Proteção Individual - EPI. ${ }^{3}$

Nas últimas décadas, o problema de saúde relacionado às atividades profissionais tem se difundido em larga escala, se transformando em condições de preocupações para os empregadores e as informações fornecidas pela Organização Internacional do Trabalho - OIT destaca que 160 milhões de trabalhadores adquirem doenças atreladas ao trabalho todos os anos. Calcula-se que 4\% do Produto Interno Bruto - PIB mundial é gasto com doenças profissionais, absenteísmo no trabalho, adoecimentos, tratamentos e pensões. ${ }^{4}$

Em meio às diversas profissões e funções desempenhadas, abordou-se o Agente Comunitário de Saúde, o qual também está exposto a situações de riscos face às funções desempenhadas por eles, não apenas no âmbito da Unidade Básica de Saúde, mas também na própria comunidade, onde desenvolve suas atividades.

As funções do Agente Comunitário de Saúde - ACS, em sua maioria, são realizadas em campo, na comunidade, por meio das visitas domiciliares, servindo de elo entre a população e a Unidade Básica de Saúde - UBS. O ACS ainda percorre ruas, casas, vielas, becos e muita das vezes têm a necessidade de acessar locais distantes e isolados, onde as 
famílias mais carentes se encontram, constituindo assim um problema na realização de suas atividades. ${ }^{5}$

Existem sempre condições e situações de risco no trabalho do Agente Comunitário de Saúde, envolvendo desde questões solidárias e sociais como de cunho tecnológico e ainda no exercício do lidar com as famílias através das visitas domiciliares, onde exerce papel social relevante e o mesmo está suscetível a situações de estresse, exaustão física no trabalho, riscos ocupacionais e até doenças infecciosas. ${ }^{6,7}$

Dessa maneira, o estudo realizado envolvendo os riscos da rotina de trabalho do ACS tornou-se relevante, devido a não identificação de estudos específicos no município e por se tratar de um problema de saúde pública, uma vez que os mesmos podem estar expostos a situações de risco, os quais quando reconhecidos precocemente possibilitam a realização de medidas preventivas, minimizando assim, o comprometimento da saúde desse trabalhador.

Com isto, neste estudo, objetivou-se investigar os riscos na rotina de trabalho do ACS em uma Equipe de Saúde da Família do município de Imperatriz- MA; destacar o perfil sociodemográfico e identificar os riscos aos quais estes ACS estão expostos na sua rotina de trabalho.

\section{Metodologia}

Estudo descritivo, de abordagem quali-quantitativa, realizada entre o período de março de 2012 a fevereiro de 2013. A análise descritiva utiliza técnicas padronizadas de coletas de dados, como o questionário e a observação sistemática, tratando-se assim, de um estudo que tem a finalidade de descrever as características de uma determinada população ou fenômeno ou ainda estabelecer relações entre as variáveis. ${ }^{8}$ O estudo tem ainda abordagem quali-quantitativa, realizado no período de março de 2012 a fevereiro de 2013.

A pesquisa em questão tem a seleção da amostra aleatória, realizada na Equipe de Saúde da Família do Parque Anhanguera do município de Imperatriz, MA. Para tanto, 
participou do estudo, cinco Agentes Comunitários de Saúde que se encontraram presentes no momento da pesquisa. A coleta de dados ocorreu no período de dezembro de 2012 a janeiro de 2013, após a aprovação do Comitê de Ética em Pesquisa - CEP do Hospital Universitário da Universidade Federal do Maranhão - HUUFMA, sob o parecer 177.582.

Foram investigadas, junto ao público-alvo, por meio da aplicação do questionário investigativo semi-estruturado, as seguintes variáveis: perfil sociodemográfico; fatores gerais relacionados ao trabalho como (carga horária de trabalho, quantidade de famílias atendidas, número de visitas domiciliares e tempo de trabalho); situações de estresse; e utilização de EPIs e relatos de exposição a situações de risco. Vale ressaltar que o questionário foi composto de questões de múltipla escolha, dando margem a ter mais de uma alternativa respondida e com perguntas abertas e fechadas.

O questionário investigativo foi aplicado mediante a assinatura do termo de autorização pelo responsável da Equipe de Saúde da Família e a concordância do ACS em assinar o Termo de Consentimento Livre e Esclarecido - TCLE, sendo realizado a leitura e esclarecimento sobre a participação na pesquisa, conforme preconizado na resolução 196/96 do Conselho Nacional de Saúde.

Foi informado ao participante que os riscos e desconfortos da sua participação são caracterizados por recordações e sentimentos provocados pelas perguntas, além de risco moral caracterizado pela divulgação das informações coletadas, sendo que o entrevistado poderia negar-se a responder qualquer questão sem sofrer nenhuma penalidade. Foi também preservado a privacidade do entrevistado, bem como, esclarecido que a pesquisa não trará nenhum ônus e bônus e garante o direito de retirada sem prejuízos a qualquer momento e receber uma cópia do TCLE.

As variáveis quantitativas foram analisadas, mediante utilização do programa Excel ${ }^{\circledR}$ (Microsoft, versão 2007) e apresentadas sob a forma de tabelas, gráfico e porcentagem.

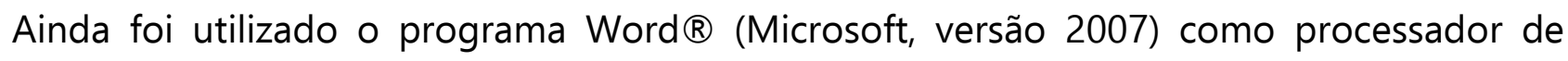
texto. As questões qualitativas foram descritas de acordo com os objetivos e 
fundamentadas nos princípios clássicos de Minayo, ${ }^{9}$ que considera as informações como o produto final da análise de uma pesquisa, e que deve ser sempre encarado como provisório e aproximativo, por mais brilhante que seja. E, para expressar os sujeitos considerando o direito ao sigilo de identidade, adotou-se a nomenclatura com nomes de pedras preciosas.

\section{Resultados}

No tocante ao perfil sociodemográfico dos Agentes Comunitários de Saúde investigados tem-se a Tabela 1.

O sexo predominante foi o feminino (100\%; $n=5)$, idade entre $31-45$ anos (40\%; $n=2)$; grau de instrução ensino médio (80\%; $n=4)$; estado civil - casado(a) (60\%; $n=2)$; renda mensal: 1 a 2 salários mínimos a amostra em sua totalidade (100\%; $n=5)$.

A Tabela 2 traz a descrição dos fatores gerais relacionados ao serviço dos Agentes Comunitários de saúde, no que diz respeito às famílias cadastradas por ACS, visitas domiciliares VD/por semana, carga horária/dia, tempo de trabalho e meio de transporte utilizado.

Para os fatores considerados estressores na rotina de trabalho dos Agentes Comunitários de Saúde da Equipe de Saúde da Família do Parque Anhanguera, do município de Imperatriz, MA (Tabela 3) foi destacado a relação com o colega e comunidade para $3(60 \%)$ respectivamente.

Em se tratando da relação dos entrevistados com seus superiores, 3 (60\%) afirmou ser amigável e 2 (40\%) referiu ser estritamente profissional.

Quanto aos riscos identificados na rotina de trabalho dos ACS da ESF do Parque Anhanguera, os resultados relatados encontram-se na Tabela 4. 
Tabela 1. Perfil sociodemográfico dos ACS investigados da ESF do Parque Anhanguera, do município de Imperatriz, MA, 2013.

\begin{tabular}{|c|c|c|}
\hline Variável & Frequência Absoluta & $\begin{array}{l}\text { Frequência Relativa } \\
\qquad(\%)\end{array}$ \\
\hline \multicolumn{3}{|l|}{ Sexo } \\
\hline Feminino & 5 & 100 \\
\hline Masculino & 0 & - \\
\hline Total & 5 & 100 \\
\hline \multicolumn{3}{|l|}{ Idade } \\
\hline $18-30$ & 0 & - \\
\hline $31-45$ & 3 & 60 \\
\hline $46-55$ & 2 & 40 \\
\hline $56-65$ & 0 & - \\
\hline Total & 5 & 100 \\
\hline \multicolumn{3}{|l|}{ Grau de Instrução } \\
\hline Analfabeto & 0 & - \\
\hline Ensino Fundamental & 1 & 20 \\
\hline Ensino Médio & 4 & 80 \\
\hline Ensino Superior & 0 & - \\
\hline Total & 5 & 100 \\
\hline \multicolumn{3}{|l|}{ Estado Civil } \\
\hline Casado(a) & 3 & 60 \\
\hline Solteiro(a) & 1 & 20 \\
\hline Divorciado(a) & 1 & 20 \\
\hline Viúvo(a) & 0 & - \\
\hline Outros & 0 & - \\
\hline Total & 5 & 100 \\
\hline \multicolumn{3}{|l|}{ Renda Mensal } \\
\hline Sem renda & 0 & - \\
\hline Menos de um salário & 0 & - \\
\hline 1 a 2 salários & 5 & 100 \\
\hline 3 a 4 salários & 0 & - \\
\hline Total & 5 & 100 \\
\hline
\end{tabular}


Fonte: Elaborado pelos autores (2013). 
Tabela 2. Distribuição dos fatores gerais relacionados ao trabalho dos ACS da ESF do Parque Anhanguera, do município de Imperatriz, MA, 2013.

\section{Variável}

Frequência

Frequência

Absoluta

Relativa (\%)

Famílias cadastradas por ACS

\begin{tabular}{lcc} 
Menos de 100 & 0 & - \\
De 100 a 149 & 4 & 80 \\
Mais de 150 & 1 & 20 \\
Não sabe relatar & 0 & - \\
\hline Total & 5 & 100 \\
Visitas domiciliares (VD)/semana & & \\
Menos de 10 & 0 & - \\
10 a 19 & 0 & 100 \\
20 a 40 & 5 & - \\
Não sabe relatar & 0 & 100 \\
Total & 5 &
\end{tabular}

Carga horária/dia

Menos de $8 \mathrm{~h}$

$8 \mathrm{~h}$

0

Mais de $8 \mathrm{~h}$

5

100

Não sabe relatar

0

Total

5

100

Tempo de trabalho

Menos de 1 ano

1 a 4 anos

20

5 a 9 anos

Mais de 10 anos

$4 \quad 80$

Total

5

100

Meio de transporte utilizado

\begin{tabular}{lcc} 
A pé & 5 & 100 \\
Bicicleta & 0 & - \\
Automóvel & 0 & - \\
Motocicleta & 0 & - \\
\hline otal & 5 & 100
\end{tabular}

Fonte: Elaborado pelos autores (2013). 
Tabela 3. Distribuição dos fatores considerados estressores na rotina de trabalho dos ACS da ESF do Parque Anhanguera, do município de Imperatriz, MA, 2013.

\begin{tabular}{lcc}
\multicolumn{1}{c}{ Variável } & $\begin{array}{c}\text { Frequência } \\
\text { Absoluta }\end{array}$ & $\begin{array}{c}\text { Frequência relativa } \\
\text { (\%) }\end{array}$ \\
\hline Situação estressante & 1 & 20 \\
Relação com o chefe & 3 & 60 \\
Relação com o colega & 3 & 60 \\
Relação com a comunidade & 0 & - \\
\hline Deslocamento & 7 & 140 \\
\hline Total & & \\
\hline Relação com o chefe & 2 & 40 \\
Estritamente profissional & 3 & - \\
Amigável & 0 & - \\
Conflituosa & 0 & 100 \\
\hline Não tem relação nenhuma & 5 & 00 \\
\hline Total & &
\end{tabular}

Nota: Na variável, situação estressante, a soma dos percentuais excede $100 \%$ em função dos ACS terem respondido mais de uma alternativa. Fonte: Elaborado pelos autores (2013).

Tabela 4. Exposição a riscos pelos ACS da ESF do Parque Anhanguera, do município de Imperatriz, MA, 2013.

\begin{tabular}{lcc}
\multicolumn{1}{c}{ Variável } & $\begin{array}{c}\text { Frequência } \\
\text { Absoluta }\end{array}$ & $\begin{array}{c}\text { Frequência } \\
\text { relativa (\%) }\end{array}$ \\
Riscos & 5 & 100 \\
Exposição solar & 5 & 100 \\
Doenças Infectocontagiosas & 0 & - \\
Acidentes de percurso & 3 & 60 \\
Exposição a chuvas & 0 & - \\
Poeira & 0 & - \\
Fumaça & 0 & - \\
Nenhum & 0 & - \\
Outros & 13 & 260 \\
\hline Total &
\end{tabular}

Nota: a soma dos percentuais excede $100 \%$ em função dos ACS terem respondido mais de uma alternativa. Fonte: Elaborado pelos autores (2013). 
Nesta abordagem, destacaram-se riscos biológicos como as doenças infectocontagiosas 5 (100\%) visto que, o ACS tem dentre suas atribuições a realização de visitas domiciliares e na realização dessas visitas tem contato com pessoas com doenças contagiosas, neste aspecto os resultados corroboram com o estudo exploratório de caráter participativo de Nascimento.

Neste sentido, os agentes envolvidos foram categorizados sobre a denominação de pedras preciosas, que garante a privacidade da identidade ao emitirem suas respostas sobre a abordagem do estudo, como seguem:

"Considero as doenças infecciosas um risco muito grande, por exemplo, quando entro na casa eu não uso nada que me proteja de alguma doença que eu possa pegar" (RUBÍ).

"Com certeza, as doenças contagiosas por que trabalho em contato constante com as famílias e quase sempre tem alguém na casa que tá com alguma doença transmissível" (SAFIRA).

"Eu acho risco as doenças transmissíveis porque realizo visita domiciliar e entro nas casas e lá pode sempre ter alguém doente com uma doença contagiosa" (DIAMANTE).

"As doenças contagiosas. Porque na comunidade é encontrada doenças de todo tipo inclusive as que transmite de uma pessoa pra outra e eu tô sempre lá nas casas fazendo visita domiciliar" (ESMERALDA).

"Sem dúvida as doenças transmissíveis por trabalhar em contato com a comunidade doente quando faço as visitas domiciliares" (PÉROLA).

Neste aspecto, os relatos dos ACS são descritos como segue:

"O sol com certeza. Aqui parece que o sol é mais quente do que nos outros lugares, então queima demais. Eu tenho até medo de ter problema de câncer de pele um dia [...]" (RUBÍ).

"O sol sem dúvida é um risco. Andamos a comunidade toda a pé até chegar na casa de alguém e até chegar lá pegamos o sol todinho [...] também tem a questão das chuvas que dependendo do período pegamos muito" (SAFIRA).

"O sol. Me incomoda muito, arde a pele da gente toda, fico toda queimada [...] e tem também as chuvas que quando tá no período chuvoso a gente pega direto" (DIAMANTE). 
"O sol com certeza é um risco grande porque quando vamos fazer as visitas no caminho pegamos muito sol e a pele fica toda queimada e com manchas [...]" (ESMERALDA).

"Eu considero o sol um risco muito grande. Porque quase todo dia pego sol direto quando vou fazer as visitas nas comunidades [...] a chuva também é outro risco porque aqui quando tá na época de chuva chove de uma hora pra outra aí não tem jeito se molha mesmo e as vezes tô até com o corpo quente" (PÉROLA).

Em se tratando dos Equipamentos de Proteção Individual dentre os ACS, 4 (80\%) referiram fazer uso do protetor solar (Tabela 5).

Tabela 5. EPI utilizados pelos ACS da ESF do Parque Anhanguera, do município de Imperatriz, MA, 2013.

\begin{tabular}{llc}
\multicolumn{1}{c}{ Variável } & $\begin{array}{c}\text { Frequência } \\
\text { Absoluta }\end{array}$ & $\begin{array}{c}\text { Frequência relativa } \\
(\%)\end{array}$ \\
\hline EPI & 4 & 80 \\
Protetor solar & 0 & - \\
Luvas & 0 & - \\
Máscaras & 0 & - \\
Capas de chuva & 1 & 20 \\
Camisa de manga longa & 1 & 20 \\
Sapato fechado & 0 & - \\
Nenhum & 0 & - \\
\hline Outros & 6 & 120 \\
\hline Total & &
\end{tabular}

Nota: a soma dos percentuais excede $100 \%$ em função dos ACS terem respondido mais de uma alternativa. Fonte: Elaborado pelos autores (2013).

Quanto ao uso de camisas de manga longa e sapatos fechados para ambos, dentre os ACS, 1 (20\%) referiram fazer uso para proteção individual no trabalho. Considerando os riscos que o ACS está exposto, seria relevante, que os mesmos utilizassem equipamentos de Proteção Individual, como o uso de protetor solar, camisa de manga longa, bonés, 
capacete de bicicleta, meias de compressão, no intuito de proteger a sua saúde e a integridade física.

Nesta abordagem, os relatos dos ACS são descritos como segue:

"Utilizo somente protetor solar por causa do sol que é muito quente, uso pra tentar me proteger" (RUBÍ).

"O único que utilizo é o protetor solar pra ver se não aparece manchinhas na pele, o sol é quente demais" (SAFIRA).

"Uso protetor solar pra ver se não me queimo, mas não tem jeito queima do mesmo jeito" (DIAMANTE).

"Só o protetor solar, porque pego muito sol quando saio pras visitas, mas mesmo assim ainda fico toda queimada" (ESMERALDA).

"Quando vou fazer as visitas nas casas da comunidade eu uso camisa de manga longa por causa do sol e uso sapato fechado é melhor pra andar e proteger meus pés de sujeiras e ferida" (PÉROLA).

É sabido que a educação em saúde perpassa orientações e por medidas preventivas, neste sentido, os resultados de acordo com o gráfico 1, demonstrou que:

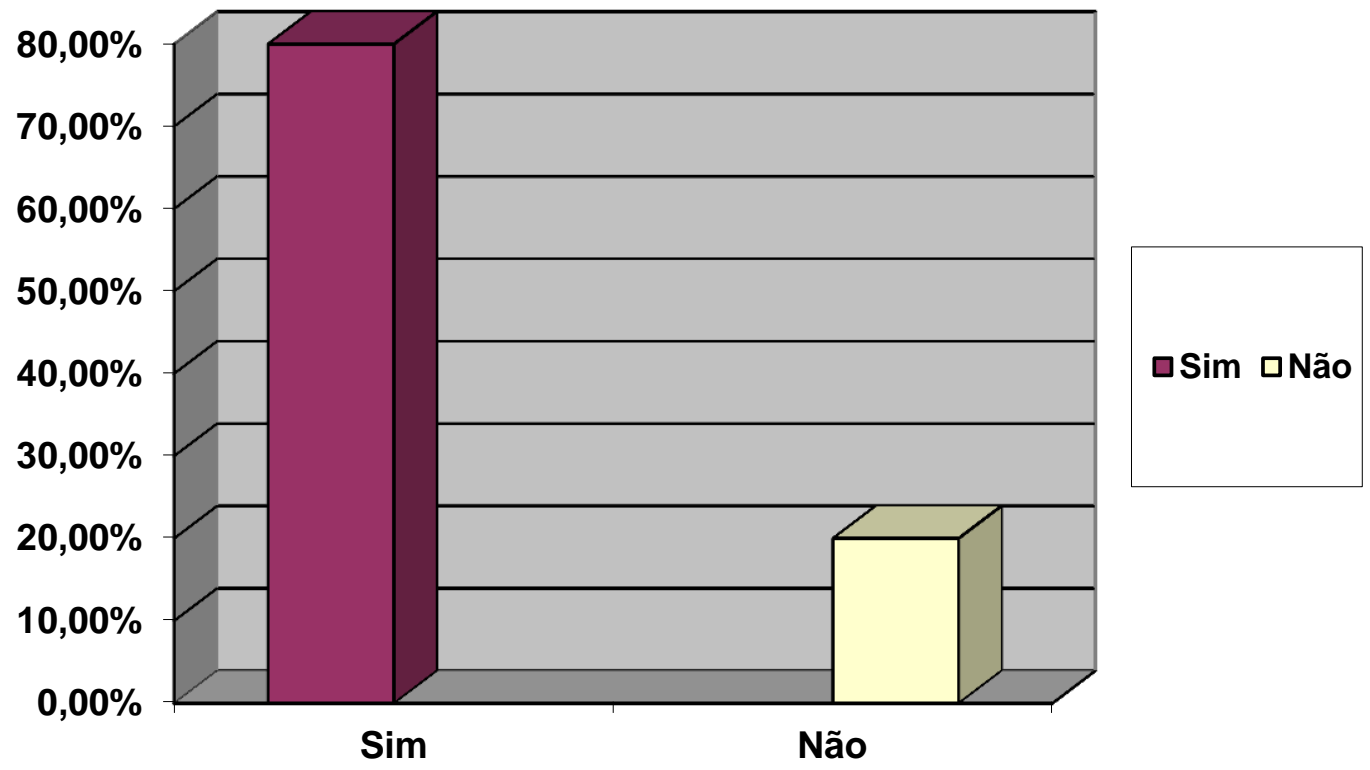

Gráfico 1. Orientação referente aos riscos e medidas de prevenção.

Fonte: Elaboração própria (2010). 
Dentre as orientações referentes aos riscos e medidas de prevenção, 4 (80\%) dos ACS informaram que receberam as referidas informações.

Com isto, considera-se relevante que o Enfermeiro como profissional responsável pela educação em saúde dentro da Equipe da Saúde da Família, proporcione orientações quanto à utilização de EPIs e dos riscos aos quais estes trabalhadores podem estar vulneráveis, especialmente pelo uso incorreto do EPI. Principalmente fundamentado na NR 32, que reitera a necessidade do conhecimento dos riscos radiológicos associados à atividade desenvolvida e o uso adequado de EPI para minimizar os riscos. ${ }^{10}$

E como respostas para estas questões, os ACS destacaram as seguintes posições:

"Recebo orientação sim. [...] Às vezes tem reunião da equipe e o enfermeiro fala dos riscos e o que a gente deve fazer pra evitar" (RUBÍ).

"Sim, recebo pelos cursos de capacitação que sempre tão realizando pra nós da equipe" (SAFIRA).

"Sim tem curso de capacitação pra gente e eles falam sobre isso [...]" (DIAMANTE).

"Sim. Tem época que tem curso de capacitação e que eles falam pra gente dos EPI" (ESMERALDA).

"Não. Eu não me lembro de ter recebido orientação sobre esse assunto" (PÉROLA).

\section{Discussão}

A predominância feminina a maior interação das mulheres junto à comunidade na realização de eventos de cunho social e trabalho voluntário, o que as aproxima das famílias e as tornam conhecedoras das realidades de cada universo familiar. Os fatores de sobrecarga e de estresse do ACS na realização de suas atividades na comunidade e UBS, onde a grande maioria dos ACS entrevistados (92,3\%) também correspondia a indivíduos do sexo feminino. ${ }^{11}$

Isso pode estar relacionado com o papel que a mulher ocupa na sociedade de cuidadora, orientadora da família, desempenhando funções de compromisso e responsabilidade na educação e saúde dos seus próximos. 
Quanto à faixa etária variou de 31 a 55 anos de idade, com média em torno de 40,2 anos. Esses resultados foram distintos aos obtidos em outros estudos descritivo de abordagem quanti-qualitativa que evidenciaram ACS inseridos na faixa etária entre 23 e 27 anos. $^{12}$

Os agentes comunitários de saúde com mais idade tendem a conhecer melhor a comunidade, ter mais vínculos e laços de amizades. Eles também têm seus próprios conceitos sobre o processo saúde-doença, advindos de experiências próprias ou alheias, podendo ser mais resistentes a novos conceitos relacionados à promoção da saúde em sua comunidade. Em contrapartida reconhecem que a possibilidade de inserção de jovens nesse contexto poderá garantir uma abertura maior para as mudanças e novidades tão necessárias para a consolidação da ESF, como uma forma de propiciar a reorganização do sistema ${ }^{13}$

No que se refere ao grau de escolaridade, quanto maior o mesmo, mais condições terá o agente comunitário de saúde de incorporar novos conhecimentos e orientar as famílias sob sua responsabilidade. Destarte, tornar um Agente Comunitário de Saúde tratase de uma oportunidade de ter uma profissão e se inserir no mercado de trabalho. ${ }^{6,13}$

É importante ainda destacar que 1 (20\%) dos entrevistados tinha o Ensino Fundamental somente, e atualmente para que se possa ser um ACS, é obrigatório ter concluído o Ensino Fundamental como determinado pela Lei $10.507 .{ }^{14}$ Nesse caso, verificou-se que 5 (100\%) dos ACS se enquadraram no que é preconizado pela lei em questão.

Com relação ao estado civil $3(60 \%)$ das entrevistadas são casadas. Tal resultado assemelha-se a outros estudos, entretanto de caráter analítico e descritivo em que $63,41 \%$ também são casadas, embora esta seja uma variável não analisada em outros estudos que trataram do trabalho dos Agentes Comunitários de Saúde (ACS). 15,16

Em se tratando da renda familiar, dentre os 5 (100\%) oscilou de 1 a 2 salários mínimos vigentes na ocasião, semelhante a outro estudo onde a renda familiar também 
variou nessa média. ${ }^{12}$

No que tange a distribuição dos fatores gerais relacionado ao trabalho dos ACS da ESF do Parque Anhanguera, 4 (80\%) atende até 149 famílias, 5 (100\%) realizam de 20 a 40 visitas domiciliares por semana e 5 (100\%) desses ACS possuem carga horária de 8 horas por dia (Tabela 2). Estes estão em conformidade com o Ministério da Saúde ${ }^{13}$ o qual preconiza que cada ACS deve atender até 750 pessoas o que corresponde em média a 150 famílias, com o mínimo de visitas domiciliares em torno de 8 por dia e todo membro da equipe de saúde, incluindo o ACS que deve cumprir uma carga horária de 40h semanais, exceto o médico.

Ressalta-se ainda, que a carga horária de 8h/dia do ACS inclui atividades interno e externamente à UBS como atender na recepção; procurar prontuários de pacientes; atender ao telefone; entregar medicação na farmácia e marcar consultas especializadas para a comunidade, por solicitação médica e realização de visitas domiciliares. ${ }^{13}$

Contudo, o número de famílias atendidas difere de outros estudos sobre o perfil e a realidade de trabalho dos ACS no Programa de Saúde da Família, em que 68,9\% dos ACS atendem em média 97 famílias. ${ }^{17}$

Em se tratando do tempo de trabalho, 4 (80\%) dos ACS estão nessa atividade há mais de 10 anos. Esse resultado é heterogêneo a outros estudos sobre as percepções a respeito de ser um ACS, em que (100\%) dos ACS tem o tempo de trabalho inferior a 10 anos. $^{18}$

Considerando o deslocamento, o meio de transporte utilizado, dentre os ACS, 5 (100\%) realizam suas visitas domiciliares a pé. Tal fato diverge de estudos sobre os principais riscos à saúde no trabalho do ACS do município de Sidrolândia-MS, em que os agentes comunitários de saúde relataram em sua totalidade utilizarem para locomoção durante a realização das visitas domiciliares uma bicicleta. ${ }^{15}$

Estes resultados corroboram estudo sobre as percepções do estresse no trabalho pelos ACS, que enfatizaram a relação com a comunidade estressante, pois ressalta que 
existem expectativas do atendimento ser realizado no momento em que as pessoas necessitam e que seus problemas sejam solucionados. Porém quando isso não acontece a população fica insatisfeita e podem ocorrer até agressões de cunho verbal ou pressão psicológica intensa. ${ }^{11}$

Contudo, divergiu de estudos ao abordar o perfil dos profissionais e a organização do trabalho no cotidiano do Programa de Saúde da Família, onde 71\% e 71,4\% dos ACS não consideram a relação com o colega e comunidade, respectivamente, estressante e sim boa. ${ }^{17}$

A cobrança excessiva, a rigidez das normas, falta de flexibilidade relacionada ao trabalho do ACS, leva ao desconforto e podem gerar tensões no trabalho. As tensões envolvidas no processo de trabalho e as respectivas ações e desempenho profissional certamente afetam a qualidade de vida do ACS. Porém, sabe-se que a relação com a equipe de trabalho é extremamente necessária para um trabalho integral e contínuo de modo que favoreça a qualidade de atendimento dos pacientes. Além disso, uma relação amigável com os membros da equipe de saúde pode evitar estresses e sofrimento emocional por parte dos ACS. ${ }^{18}$

Sobre o desenvolvimento de um método com instrumento para avaliação dos riscos no trabalho dos ACS, que cita as doenças infectocontagiosas pela exposição a pacientes portadores de doenças transmissíveis; ingestão de água não-tratada e contato com pessoas com pediculose e micose como risco encontrado na rotina de trabalho do ACS.

Dentre os riscos, encontrou-se os físicos referidos pela exposição solar por 5 (100\%) e a exposição à chuva por 3 (60\%) dos ACS entrevistados, fato este atribuído a algumas situações como por exemplo o trajeto realizado a céu aberto da UBS às casas na comunidade, deixando dessa maneira, os ACS exposto a tais riscos, os resultados assemelharam-se ao estudo de caráter analítico e descritivo de abordagem qualiquantitativa onde a exposição solar aparece como principal risco físico, havendo destaque para sinais, como manchas e queimaduras na pele do ACS, além também da exposição a 
chuva. $^{15}$

ISSN 2179-6750

Estes aspectos manifestados pelos sujeitos, se baseiam no pressuposto de que os entrevistados não são ingênuos espectadores ou atores não críticos e que os resultados da pesquisa social representam uma aproximação da realidade social. ${ }^{9}$

\section{Considerações finais}

Com a realização deste estudo, no qual de um modo geral se propôs investigar os riscos na rotina de trabalho do Agente Comunitário de Saúde da Equipe de Saúde do Parque Anhanguera foi possível concluir que:

Os riscos referidos pelos ACS foram principalmente durante a realização das visitas domiciliares com predominância dos biológicos caracterizados pelas doenças infectocontagiosas, seguido dos físicos com exposição solar.

O perfil sociodemográfico dos ACS da Equipe de Saúde da Família deste estudo teve predominância do sexo feminino, casadas, na faixa etária de 31 a 55 anos, ensino médio e renda familiar de 1 a 2 salários mínimos.

Apesar de não ter sido o foco central dessa pesquisa, investigaram-se fatores relacionados ao trabalho e concluiu-se que o deslocamento para a realização das visitas domiciliares era feito a pé; que as relações entre os colegas e comunidade foram consideradas estressantes e o Equipamento de Proteção Individual mais utilizado foi o protetor solar.

Embora o universo estudado tenha sido 100\% dos ACS da Equipe de Saúde da Família do Parque Anhanguera, estes achados não traduziram a realidade dos ACS do município, no entanto, teve relevância à medida que apontou elementos capazes de suscitarem interesse a novas pesquisas envolvendo mais profissionais desta categoria para que possa fomentar as autoridades na tomada de medidas preventivas, por se tratar de um problema de saúde pública e especialmente para conscientização dos profissionais acerca dos riscos e consequente atenção na prevenção pessoal. 


\section{Referências}

1. Brasil, Ministério da Saúde. Cadernos de atenção básica n. 41: saúde do trabalhador. Brasília, DF: MS; 2018 [citado 27 jun. 2019]. Disponível em:

http://renastonline.ensp.fiocruz.br/recursos/caderno-atencao-basica-41-saudetrabalhador-trabalhadora.

2. Cardoso ACM. O trabalho como determinante do processo saúde-doença. Tempo Soc. 2015;27(1):73. https://doi.org/10.1590/0103-207020150110.

3. Almeida MCS, Baptista PCP, Silva A. Cargas de trabalho e processo de desgaste em Agentes Comunitários de Saúde. Rev Esc Enferm USP. 2016;50(1):93-100. http://dx.doi.org/10.1590/S0080-623420160000100013.

4. Maciazeki-Gomes RS, Souza CD, Baggio L, Wachs F. O trabalho do agente comunitário de saúde na perspectiva da educação popular em saúde: possibilidades e desafios. Cienc Saude Colet. 2016;21(5):1637-46. http://dx.doi.org/10.1590/141381232015215.17112015.

5. Freire RMA, Landeiro MJL, Martins MMFPS, Martins T, Peres HHC. Um olhar sobre a promoção da saúde e a prevenção de complicações: diferenças de contextos. Rev Latino-Am Enferm. 2016;24:e2749. http://dx.doi.org/10.1590/1518-8345.0860.2749.

6. Minayo MCS. Amostragem e saturação em pesquisa qualitativa: consensos e controvérsias. Rev Pesqui Qual [Internet]. 2017[citado 21 jun. 2019;5(7):1-12. Disponível em: https://editora.sepq.org.br/index.php/rpq/article/view/82/59.

7. Brasil, Ministério da Saúde, Agência de Vigilância Sanitária. Norma Regulamentadora 32 (NR-32): segurança e saúde no trabalho em serviços de saúde. Brasília, DF: 2005.

8. Silva MA, Lampert SS, Bandeira DR, Bosa CA, Barroso SM. Saúde emocional de agentes comunitários: Burnout, estresse, bem-estar e qualidade de vida. Rev SPAGESP [Internet]. 2017[citado em 19 jun. 2019];18(1):20-33. Disponível em: http://pepsic.bvsalud.org/pdf/rspagesp/v18n1/v18n1a03.pdf.

9. Alonso CMC, Béguin PD, Duarte FJCM. Trabalho dos agentes comunitários de saúde na estratégia saúde da família: metassíntese. Rev Saude Publica. 2018;52:14. https://doi.org/10.11606/S1518-8787.2018052000395.

10. Riquinho DL, Pellini DL, Ramos DT, Silveira MR, Santos VCF. O cotidiano de trabalho do agente comunitário de saúde: entre a dificuldade e a potência. Trab Educ Saude. 
2018;16(1):163-62. http://dx.doi.org/10.1590/1981-7746-sol00086.

11. Brasil, Ministério da Saúde. Lei n 10.507, de 10 de julho de 2002. Cria a profissão de agente comunitário de saúde e dá outras providências. Brasília, DF: Diário Oficial da União; 2002 [citado em 11 jan. 2012]. Disponível em: http://www010.dataprev.gov.br.

12. Santos AC, Hoppe AS, Krug I SBF. Agente comunitário de saúde: implicações dos custos humanos laborais na saúde do trabalhador. Physis. 2018;28(4):e280403. Disponível em: http://dx.doi.org/10.1590/s0103-73312018280403.

13. Brasil, Ministério da Saúde. Portaria n² 2.488 de 21 de outubro de 2011. Brasília, DF 2011 [citado 11 jan. 2013]. Disponível em: http://bvsms.saude.gov.br.

14. Pedraza DF, Santos I. Perfil e atuação do agente comunitário de saúde no contexto da estratégia saúde da família em dois municípios da Paraíba. Interações. 2017;18(3):97-105. http://dx.doi.org/10.20435/inter.v18i3.1507.

15. Morosini MV, Fonseca AF. Os agentes comunitários na atenção primária à saúde no Brasil: inventário de conquistas e desafios. Saude Debate. 2018;42(spe 1):261-74. http://dx.doi.org/10.1590/0103-11042018S117.

16. Jesus AS, Santos FPA, Rodrigues VP, Nery AA, Machado JC, Couto TA. Atuação do agente comunitário de saúde: conhecimento de usuários. Rev Enferm UERJ [Internet]. 2014[citado em 22 jun 2019]. 22(2):239-44. Disponível em: http://www.facenf.uerj.br/v22n2/v22n2a15.pdf.

17. Barreto ICHC, Pessoa VM, Sousa MFA, Nuto SAS, Freitas RWJF, Ribeiro KG. Complexidade e potencialidade do trabalho dos agentes comunitários de saúde no Brasil contemporâneo. Saude Debate. 2018;42(spe 1):114-29. http://dx.doi.org/10.1590/0103-11042018S108. 
18. Brito RS, Ferreira NEMS, Santos DLA. Atividades dos agentes comunitários de saúde no âmbito da estratégia saúde da família: revisão integrativa da literatura. Saude Transform Soc. [Internet]. 2014[citado 27 jun. 2019];5(1):16-21. Disponível em: http://pepsic.bvsalud.org/scielo.php?script=sci_arttext\&pid=S2178 70852014000100004.

\section{Minicurrículo}

Karine da Silva Moreira | ORCiD: 0000-0001-7148-8814

Universidade Federal do Maranhão - UFMA, Departamento de Enfermagem. Imperatriz, MA, Brasil.

Maria Luiza Rêgo Bezerra | ORCiD: 0000-0002-3336-7760

Universidade Paulista - UNIP, campus Brasília, DF. Mestre em Enfermagem pela Universidade de Brasília UnB. Professora Adjunto/Profissional III do Curso de Enfermagem da UNIP. Brasília, DF, Brasil.

Cecilma Miranda de Sousa Teixeira | ORCiD: 0000-0002-7053-8602

Professora Adjunta II da Universidade Federal do Maranhão - UFMA. Universidade Evangélica del Paraguay - UEP, Validação Universidade Federal do Rio de Janeiro - UFRJ, Programa de Pós-graduação em Ciências da Educação, Asunción, DC, Paraguai. Imperatriz, MA, Brasil.

Simony Fabíola Lopes Nunes | ORCiD: 0000-0003-4613-8542

Universidade Federal de Santa Catarina - UFSC, Programa de Pós-graduação em Enfermagem, Florianópolis, SC, Brasil. Bolsista Fundação de Amparo à Pesquisa e ao Desenvolvimento Científico e Tecnológico do Maranhão - FAPEMA. Docente do curso de Enfermagem da Universidade Federal do Maranhão - UFMA-CCSST. Imperatriz, MA, Brasil. 